\title{
An investigation of agricultural use potential of dewatered sewage sludge
}

\author{
Seyed Mostafa Aghili ${ }^{* \oplus}$, Nasser Mehrdadi $^{1}{ }^{\circledR}$, Behnoush Aminzadeh $^{1}{ }^{\circledR}$, Mohammad Ali Zazouli $\left.^{(}\right)$ \\ ${ }^{1}$ Department of Environmental Engineering, School of Environment, College of Engineering, University of Tehran, Tehran, Iran \\ ${ }^{2}$ Department of Environmental Health Engineering, School of Health and Health Sciences Research Center, Mazandaran University of \\ Medical Sciences, Sari, Iran
}

\begin{abstract}
Background: One of the useful applications of Dewatered sludge (DWS) of municipal wastewater treatment plants (WWTPs) is its use as manure in agriculture; therefore, its quality characteristics should be specified. The aim of this research was to determine biological and physicochemical characteristics of DWS of Sari WWTP and compare them with standards, and also to investigate its potential use in agriculture.

Methods: Sludge samples were taken from the sewage sludge of Sari WWTP. Sampling and analysis of samples parameters including fecal coliform, salmonella, helminth ova, carbon, nitrogen, C/N, phosphorus, organic matter, potassium, moisture, electrical conductivity, and $\mathrm{PH}$, were performed during four seasons with three replications based on the standard method.

Results: The fecal coliform, salmonella, and helminth ova of the DWS were $2.37 \times 10^{6} \pm 1.06 \times 10^{6}$ MPN/1 g d.s weight, $47 \pm 12.92 \mathrm{MPN} / 4 \mathrm{~g}$ d.s weight, and $466 \pm 61.85$ number/4 $\mathrm{g}$ d.s weight, respectively, therefore, the DWS of Sari WWTP was categorized in the class B of the EPA standard. The amounts of $\mathrm{C} / \mathrm{N}$, organic matter, carbon, nitrogen, phosphorus, potassium, moisture, electrical conductivity, and $\mathrm{PH}$ were obtained to be $12.7 \pm 1.15,42.4 \pm 3.27 \%, 24.6 \pm 1.89 \%, 1.94 \pm 0.13 \%, 2.35 \pm 0.6 \%, 0.57 \pm 0.13 \%$, $82 \pm 3.12 \%, 1.34 \pm 0.21 \mathrm{ds} / \mathrm{m}$, and $7.41 \pm 0.45$, respectively.

Conclusion: The DWS of Sari WWTP has a good fertility value but it cannot be safely used in agriculture and should be improved for class A by the Processes to Further Reduce Pathogens (PFRP), especially by composting.

Keywords: Sewage sludge, Agricultural use, Fertilizer, Pollution control, Dewatered sludge

Citation: Aghili SM, Mehrdadi N, Aminzadeh B, Zazouli MA. An investigation of agricultural use potential of dewatered sewage sludge. Environmental Health Engineering and Management Journal 2019; 6(3): 179-184. doi: 10.15171/EHEM.2019.20.
\end{abstract}

Article History:

Received: 17 February 2019

Accepted: 24 June 2019

ePublished: 10 July 2019

\section{Introduction}

Disposal of excess sludge from sewage treatment is an essential requirement for wastewater treatment plants (WWTPs). Dewatered sludge (DWS) generated from municipal wastewater treatments, has useful applications. One of the most appropriate useful applications of DWS is its use as manure in agriculture because DWS is known as a biological product compatible with the environment and full of reinforce nutrients for agricultural soil, and also, as a suitable alternative for chemical nitrogen and phosphorus manures (1-3). Given its enrichment in nutrients, such as nitrogen, phosphorus, and potassium, sludge can be used as soil conditioners and fertilizers to enhance agricultural products (4). But DWS contains many pollutants such as fecal coliform, salmonella, virus, helminth ova, and heavy metals that limit its use in agriculture $(5,6)$. In the provisions of 40 CFR part 503 of EPA, DWS is divided into two classes of $\mathrm{B}$ and $\mathrm{A}$. The purpose of the sludge class $B$ regulations is to reduce the fecal coliform to less than 2 million MPN/g d.s weight. Therefore, class B sludge is used only under strictly defined conditions and with strict agricultural constraints. The main purpose of the class A regulations is to reduce fecal coliform to less than 1000 MPN/g d.s weight, salmonella to less than $3 \mathrm{MPN} / 4 \mathrm{~g}$ d.s weight, the intestinal virus to less than $1 \mathrm{PFU} / 4 \mathrm{~g}$ d.s weight, and helminth ova to less than 1 ova/4 $\mathrm{g}$ d.s weight. Therefore, there is no limitation for the use of class $\mathrm{A}$ sludge in agriculture $(7,8)$.

Sewage sludge may be stabilized by aerobic digestion such as composting, or anaerobic digestion $(9,10)$. Literature review shows that sludge qualities are different in various WWTPs in the world and Iran, so that sludge quality of 
domestic sewage treatment in the city of Franca in Brazil was in the standard class B (11); but evaluation of the quality of sewage sludge in the city of Sarkan in Hamedan and its comparison with environmental standards for reuse showed that the characteristics of sludge produced had a significant difference with those of the class $\mathrm{A}$ and class B (12); on the other hand, the sludge of Shosh's wastewater treatment was classified in none of the classes (13), while sludge quality in Isfahan WWTP was classified in class B (14).

WWTP of Sari in Mazandaran province of Iran has been designed for a population of 420,000 people in 4 modules by aerobic method. The capacity of each module is 24242 cubic meters per day $\left(\mathrm{m}^{3} / \mathrm{d}\right)$, which is designed for 105,000 people. At present, the first module with a capacity of $19500 \mathrm{~m}^{3} / \mathrm{d}$ is in operation and produces $1-3$ tone DWS per day. By adding the next three modules, the amount of DWS produced will be significant. So, useful application of the DWS in agriculture, fertilizing the soil, and making money from creating manure by the compost of DWS are necessary.

The objective of this research was to determine the physicochemical and biological characteristics of DWS of Sari WWTP and compare them with standards, and also, to determine the fertility value and class of DWS of this plant and the potential for its use in agriculture.

\section{Materials and Methods}

This case study was conducted in Sari WWTP from April 2017 and lasted four seasons of the year. Since no qualitative study had been carried out on the DWS of Sari WWTP, it was necessary to test the sludge samples in the laboratory of the School of Health of Mazandaran University of Medical Sciences (MAZUMS) and provide the qualitative characteristics of the sludge to determine the class of the sludge. DWS samples were taken from the belt filter. Sterile containers were used for biological tests and to prevent the change of samples, they were kept at a temperature between 0 and $4^{\circ} \mathrm{C}$ until they were transferred to the laboratory. The biological parameters included fecal coliform, salmonella, and helminth ova. Fecal coliform was measured by MPN standard method $9221 \mathrm{E}$. The gas in the tubes containing Brilliant Green Agar culture medium in an autoclave at $44.5^{\circ} \mathrm{C}$ for 24 hours indicates that the test is positive. Salmonella was measured using counting in Xylose Lysine Deoxycholate (XLD) agar culture medium by standard method $9260 \mathrm{D}$ (15). Helminth ova was measured according to EPA guideline (16).

The chemical parameters included C, N, C/N, phosphorus, organic matter (OM), and potassium. Total organic carbon (TOC) was measured by cold Walkley-Black method and the organic carbon of DWS was digested and oxidized by potassium dichromate in the presence of sulfuric acid. Total Kjeldahl nitrogen (TKN) was measured by the Kjeldahl method. The main purpose of this method is to convert nitrogen of DWS to ammonium and determine the concentration of ammonia nitrogen. Sulfuric acid and salts are were used to convert organic nitrogen to ammonium. Organic matter was measured by cold Walkley-Black. Phosphorus was measured by Olsen method and spectrophotometer at wavelength of $470 \mathrm{~nm}$. $50 \mathrm{~g}$ of sodium bicarbonate was added to $2.5 \mathrm{~g}$ of DWS. After passing through the Whatman filter, $5 \mathrm{~mL}$ of the ammonium heptamolybdate vanadate solution was added to the solution, and then, the absorbance was measured by the spectrophotometer. Potassium was measured by the photometric method at wavelength of $598 \mathrm{~nm}$. Moisture, the physical parameter, was measured by gravimetric method at temperature of $105^{\circ} \mathrm{C}$ for 24 hours. EC and $\mathrm{PH}$, the physicochemical parameters, were measured by conductivity meter and SW-9045D potentiometric method, respectively (15). The medium and standard deviation of all parameters were obtained by SPSS version 24 .

\section{Results}

Biological characteristics of DWS of Sari WWTP

The results of measurement of biological characteristics of DWS and standards are presented in Table 1.

\section{Physicochemical characteristics of DWS of Sari WWTP}

The results of measurement of physicochemical characteristics of DWS and standards are presented in Table 2 .

\section{Discussion \\ Fecal coliform}

Fecal coliform is the main index of the determinant of sludge class based on the provisions of CFR 40 Section 503 of the EPA standard (8). For class B sludge, reaching to the Processes to Significantly Reduce Pathogens (PSRP) standard of sludge and reduction of fecal coliform to less than 2 million MPN/g d.s weights are considered. For class A sludge, reaching to the Processes to Further Reduce Pathogens (PFRP) standard of sludge and reduction of fecal coliform to less than $1000 \mathrm{MPN} / \mathrm{g}$ d.s weight are considered. In this research, the average fecal coliform of DWS of Sari WWTP in the four seasons of the year was $2.37 \times 10^{6} \mathrm{MPN} / \mathrm{g}$ d.s weight; therefore, it was categorized in class $\mathrm{B}$, which is consistent with the results of the studies by Moretti et al (11) and Hait and Tare (7). Moretti et al investigated the sewage sludge of the domestic sewage treatment plant in the city of Franca (São Paulo, Brazil) and found that fecal coliform was $1.2 \times 10^{6} \mathrm{MPN} / \mathrm{g}$ d.s weight (11). Hait and Tare investigated the sewage sludge of the urban sewage treatment plant at Jajmau (Kanpur, India) and found that the fecal coliform was $4.5 \times 10^{7}$ MPN/g d.s weight (7). So, the DWS of Sari WWTP was categorized in the class B.

Salmonella

Another indicator of the sludge class, based on the EPA 


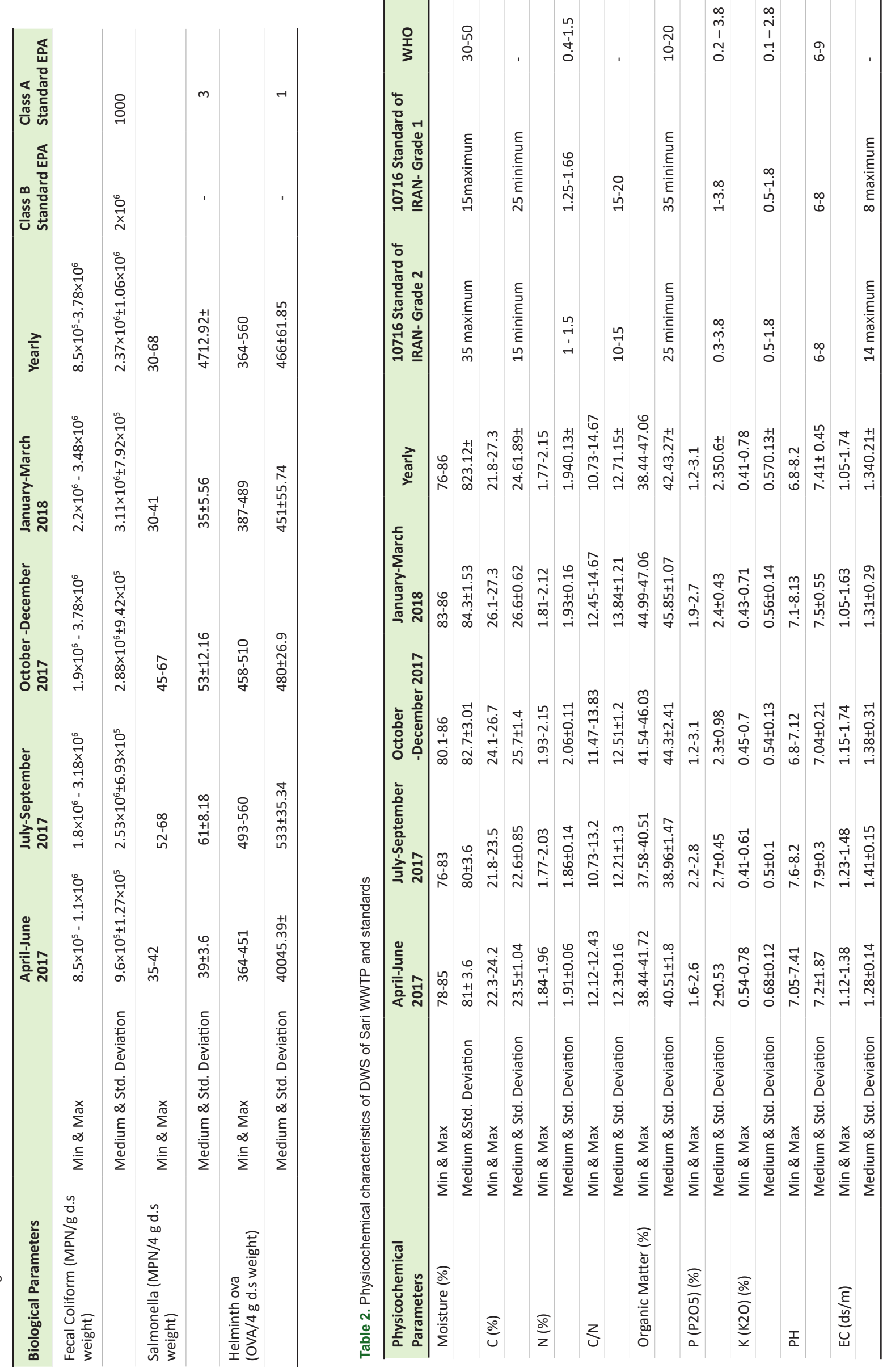


standard, is the reduction of salmonella to less than $3 \mathrm{MPN} / 4 \mathrm{~g}$ d.s weight $(7,8)$. In this study, the average salmonella of DWS in the four seasons was $47 \mathrm{MPN} / 4 \mathrm{~g}$ d.s weight, which was much higher than the EPA standard, indicating that the DWS of Sari WWTP was in the class Bazrafshan et al investigated the DWS of Isfahan sewage treatment plant and found that the salmonella was 20.45 MPN/4g d.s weight (17). The average salmonella in a study by Dumontet et alwas $24 \mathrm{MPN} / 4 \mathrm{~g}$ d.s weight, therefore, it was categorized in the class B (18).

\section{Helminth ova}

The other indicator of the sludge class in accordance with the EPA standard, is the reduction of helminth ova to less than 1 ova $/ 4 \mathrm{~g}$ d.s weight $(7,8)$. In this study, the average number of helminth ova of DWS in the four seasons was 466 , which is consistent with the results reported by Navarro and Jimenez who reported that the amount of helminth ova for developing countries was 70-735 (19). So, the DWS of Sari WWTP was in the class B (19).

\section{$\mathrm{C} / \mathrm{N}$}

The $\mathrm{C} / \mathrm{N}$ ratio is the main indicator of sludge stabilization (20). The ratio of 25 and 50 is suitable for aerobic composting. The optimum range for most organic wastes is from 20 to 25 . This ratio for sludge should be in the range of 20-30 (21) or 25-30 (22). In lower ratios, ammonia is released and microbial activities are delayed and in higher ratios, nitrogen can be a limiting nutrient (23). The wastewater treatment sludge has a low $\mathrm{C} / \mathrm{N}$ ratio. In this study, the $\mathrm{C} / \mathrm{N}$ ratio of DWS was 12.7 , which is less than those reported by Mokhtari et al, Alidadi et al, and Parvaresh et al, that were obtained to be 24, 29, and 20.38, respectively (24-26), but it was a little more than those reported by Nikaeen et al (27) and Zorpas and Loizidou (28), which were 13.7 and 10, respectively. So, it is necessary to compost DWS of sari WWTP to add bulking agents for increasing the $\mathrm{C} / \mathrm{N}$ ratio because the carbon of bulking agents is more than that of the DWS.

\section{Phosphorus}

Phosphorus is the essential mineral for plant growth. The shortage of phosphorus in the plant leads to its growth delay (29). In this research, the average phosphorus in the four seasons was $2.35 \%$, which is consistent with those reported by Cai et al (30) and Zorpas and Loizidou (28). However, it is more than that reported by Rihani et al (31), which was 1.3 and less than the results reported by Yanez et al (32) and Roca-Perez et al (33) that was $4.85 \%$ and $3.6 \%$, respectively, in the range of $1-3.8 \%$ of manure grade 1 of 10716 standard of Iran. So, DWS of Sari WWTP in terms of phosphorus is good for agriculture.

\section{Organic matter}

The organic matter is one of the stabilization indicators of DWS and it should be more than $25 \%$ so that it can be suitable for soil enrichment $(3,28)$. In this research, the average organic matter in DWS in the four seasons was $42.4 \%$, which was consistent with those reported by Zorpas and Loizidou (28) and Nikaeen et al (27). However, it was less than the results reported by Roca-Perez et al and Ponsá et al that were $60 \%$ and $75 \%$, respectively. Nevertheless, it was higher than the result reported by Rahmani et al, which was 37\% (33-35), and higher than at least $35 \%$ of manure grade 1 of standard 10716 of Iran. So, DWS of sari WWTP in terms of organic matter is good for agriculture.

\section{Potassium}

Potassium is another essential mineral for plant growth. In this research, the average potassium of DWS in the four seasons was $0.57 \%$, which was a little less than the results reported by Rihani et al (31) and Yañez et al (32), and Zorpas and Loizidou (28), which were $0.69 \%, 0.83 \%$, and $0.72 \%$, respectively, and a little more than that reported by Roca-Perez et al (0.3\%) (33), therefore, it was categorized in the range of $0.5 \%-1.8 \%$ of manure grade 1 of standard 10716. So, DWS the Sari WWTP in terms of potassium is good for agriculture.

\section{Electrical conductivity and $\mathrm{pH}$}

Electrical conductivity represents the concentration of dissolved salts in the DWS. High electrical conductivity causes soil salinity, biological toxicity, and leads to delayed germination and longitudinal growth of roots. The average percentage of electrical conductivity of DWS in the four seasons was $1.34 \mathrm{~d} . \mathrm{s} / \mathrm{m}$, which was consistent with the results reported by Zhang et al (36), indicating that it was in the range of manure grade 1 of standard 10716 of Iran. PH is one of the most important factors affecting microbial activity. The average PH of DWS in the four seasons was 7.41, which was consistent with the results of another study (37), it was in the range of manure grade 1 of standard 10716 of Iran. So, DWS of Sari WWTP in terms of Electrical Conductivity and $\mathrm{PH}$ is good for agriculture.

\section{Moisture}

Moisture carries dissolved nutrients into microorganisms and organic matter decomposition depends on the presence of moisture. Low moisture causes dehydration and slowing down the biological process. High humidity causes blockage of pores, disrupts aeration, and creates anaerobic conditions (38). The average percentage of moisture of DWS in the four seasons was $82 \%$, which was consistent with those reported by Kulikowska and Sindrewicz (39) and was less than at maximum 35\% of manure grade 2 of standard 10716 of Iran. So, at present, DWS of Sari WWTP in terms of moisture is not good for agriculture and its moisture should be reduced before the use. 


\section{Conclusion}

According to the results, produced DWS in terms of phosphorus, potassium, $\mathrm{EC}$, and $\mathrm{pH}$ is in the range of Grade 1 of Iran's manure 10716 standard. Also, the DWS in terms of $\mathrm{C}$ and $\mathrm{C} / \mathrm{N}$ is in the range of Grade 2 of this standard, and in terms of $\mathrm{N}$ and organic matter, it is higher than the range of Grade 1 of this standard, but in terms of moisture is lower than the range of Grade 2 of this standard. Accordingly, it can be concluded that DWS of Sari WWTP has a good fertility value but it cannot be safely used in agriculture and should be improved for class A by composting. Also, due to the low $\mathrm{C} / \mathrm{N}$ ratio of DWS, it is necessary to add bulking agents for increasing this ratio.

\section{Acknowledgements}

The authors would like to thank the Mazandaran Wastewater Company for supporting this study and Faculty of Health, Mazandaran University of Medical Sciences for collaboration in this research project.

\section{Ethical issues}

The authors hereby certify that all data collected during the research are as expressed in the manuscript, and no data from the study has been or will be published elsewhere separately.

\section{Competing interests}

The authors have declared that they have no conflict of interests.

\section{Authors' contribution}

All authors contributed in data collection, analysis, and interpretation. All authors reviewed, refined, and approved the manuscript.

\section{References}

1. Komilis D, Kontou I, Ntougias S. A modified static respiration assay and its relationship with an enzymatic test to assess compost stability and maturity. Bioresour Technol 2011; 102(10): 5863-72. doi: 10.1016/j.biortech.2011.02.021.

2. Glab T, Zabinski A, Sadowska U, Gondek K, Kopec M, Mierzwa-Hersztek M, et al. Effects of co-composted maize, sewage sludge, and biochar mixtures on hydrological and physical qualities of sandy soil. Geoderma 2018; 315: 27-35. doi: 10.1016/j.geoderma.2017.11.034.

3. Lu LA, Kumar M, Tsai JC, Lin JG. High-rate composting of barley dregs with sewage sludge in a pilot scale bioreactor. Bioresour Technol 2008; 99(7): 2210-7. doi: 10.1016/j. biortech.2007.05.030.

4. Wu C, Li W, Wang K, Li Y. Usage of pumice as bulking agent in sewage sludge composting. Bioresour Technol 2015; 190: 516-21. doi: 10.1016/j.biortech.2015.03.104.

5. Mosquera-Losada MR, Munoz-Ferreiro N, RigueiroRodriguez A. Agronomic characterisation of different types of sewage sludge: policy implications. Waste Manag 2010; 30(3): 492-503. doi: 10.1016/j.wasman.2009.09.021.
6. Fountoulakis MS, Makridis L, Pirounaki EK, Chroni C, Kyriacou A, Lasaridi K, et al. Fate and effect of linuron and metribuzin on the co-composting of green waste and sewage sludge. Waste Manag 2010; 30(1): 41-9. doi: 10.1016/j.wasman.2009.08.014.

7. Hait S, Tare V. Optimizing vermistabilization of waste activated sludge using vermicompost as bulking material. Waste Manag 2011; 31(3): 502-11. doi: 10.1016/j. wasman.2010.11.004.

8. Smith SR. A critical review of the bioavailability and impacts of heavy metals in municipal solid waste composts compared to sewage sludge. Environ Int 2009; 35(1): 14256. doi: 10.1016/j.envint.2008.06.009.

9. Aghili SM, Mehrdadi N, Zazouli MA, Aminzadeh B. Heavy Metal Concentrations in Dewatered Sludge of Wastewater Treatment Plant in Sari, Iran. Journal of Mazandaran University of Medical Sciences 2019; 28(170): 152-9. [In Persian].

10. Zazouli MA, Asgharnia H, Yazdani Cherati J, Ziaee Hezarjeribi H, Ahmadnezhad A. Evaluation of Cow Manure Effect as Bulking Agent on Concentration of Heavy Metals in Municipal Sewage Sludge Vermicomposting. Journal of Mazandaran University of Medical Sciences 2015; 25(124): 152-69. [In Persian].

11. Moretti SM, Bertoncini EI, Abreu-Junior CH. Composting sewage sludge with green waste from tree pruning. Sci Agric 2015; 72(5): 432-9. doi: 10.1590/0103-9016-2014-0341.

12. Farzadkia M, Taher khani H. Evaluation of Sludge Management in Sewage Treatment Plant in Hamadan Province. Journal of Mazandaran University of Medical Sciences 2005; 15(47): 19-25. [In Persian].

13. Mesdaghinia AR, Panahi Akhavan M, Vaezi F, Naddafi K, Moosavi GH. Waste sludge characteristics of a wastewater treatment plant compared with environmental standards. Iran J Public Health 2004; 33(1): 5-9.

14. Rahmani HR, Rezaei H, Amin MM, Kohanestani ZM. Investigation of sewage sludge quality for land application: a case study: two Isfahan wastewater treatment plans. Int J Env Health Eng 2015; 4: 36.

15. Dehghan S, Zazouli MA. Guidance on Sampling and Analysis of Waste and Compost. Tehran: Avaye Ghalam; 2015. [In Persian].

16. EPA (Environmental Protection Agency). A Plain English Guide to the EPA Part 503 Biosolids Rules. Washington, DC: EPA; 1994.

17. Bazrafshan E, Zazouli MA, Bazrafshan J, Mohseni-Bandpei A. Co-composting of dewatered sewage sludge with sawdust. Pak J Biol Sci 2006; 9(8): 1580-3. doi: 10.3923/ pjbs.2006.1580.1583.

18. Dumontet S, Dinel H, Baloda SB. Pathogen reduction in sewage sludge by composting and other biological treatments: A review. Biol Agric Hortic 1999; 16(4): 409-30. doi: $\quad 10.1080 / 01448765.1999 .9755243$.

19. Navarro I, Jimenez B. Evaluation of the WHO helminth eggs criteria using a QMRA approach for the safe reuse of wastewater and sludge in developing countries. Water Sci Technol 2011; 63(7): 1499-505. doi: 10.2166/wst.2011.394.

20. Chang JI, Hsu TE. Effects of compositions on food waste composting. Bioresour Technol 2008; 99(17): 8068-74. doi: 10.1016/j.biortech.2008.03.043.

21. Tchobanoglous G, Theisen H, Vigil SA. Integrated 
Solid Waste Management: Engineering Principles and Management Issues. US: McGraw-Hill; 1993.

22. Kumar M, Ou YL, Lin JG. Co-composting of green waste and food waste at low C/N ratio. Waste Manag 2010; 30(4): 602-9. doi: 10.1016/j.wasman.2009.11.023.

23. Guo R, Li G, Jiang T, Schuchardt F, Chen T, Zhao Y, et al. Effect of aeration rate, $\mathrm{C} / \mathrm{N}$ ratio and moisture content on the stability and maturity of compost. Bioresour Technol 2012; 112: 171-8. doi: 10.1016/j.biortech.2012.02.099.

24. Mokhtari M, Nikaeen M, Amin MM, Bina B, Hasanzadeh A. Evaluation of stability parameters in in-vessel composting of municipal solid waste. Iran J Environ Health Sci Eng 2011; 8(4): 325-32.

25. Alidadi H, Parvaresh AR, Shahmansouri MR, Pourmoghadas H, Najafpoor AA. Combined compost and vermicomposting process in the treatment and bioconversion of sludge. Pak J Biol Sci 2007; 10(21): 3944-7.

26. Parvaresh A, Shahmansouri MR, Alidadi H. Determination of carbon/nitrogen ratio and heavy metals in bulking agents used for sewage composting. Iran J Public Health 2004; 33(2): 20-3.

27. Nikaeen M, Nafez AH, Bina B, Nabavi BF, Hassanzadeh A. Respiration and enzymatic activities as indicators of stabilization of sewage sludge composting. Waste Manag 2015; 39: 104-10. doi: 10.1016/j.wasman.2015.01.028.

28. Zorpas AA, Loizidou M. Sawdust and natural zeolite as a bulking agent for improving quality of a composting product from anaerobically stabilized sewage sludge. Bioresour Technol 2008; 99(16): 7545-52. doi: 10.1016/j. biortech.2008.02.014.

29. Manna MC, Ghosh PK, Ghosh BN, Singh KN. Comparative effectiveness of phosphate-enriched compost and single superphosphate on yield, uptake of nutrients and soil quality under soybean-wheat rotation. J Agric Sci 2001; 137(1): 45-54. doi: 10.1017/S0021859601008942.

30. Cai QY, Mo CH, Wu QT, Zeng QY, Katsoyiannis A. Concentration and speciation of heavy metals in six different sewage sludge-composts. J Hazard Mater 2007; 147(3): 1063-72. doi: 10.1016/j.jhazmat.2007.01.142.
31. Rihani M, Malamis D, Bihaoui B, Etahiri S, Loizidou M, Assobhei O. In-vessel treatment of urban primary sludge by aerobic composting. Bioresour Technol 2010; 101(15): 5988-95. doi: 10.1016/j.biortech.2010.03.007.

32. Yañez R, Alonso JL, Diaz MJ. Influence of bulking agent on sewage sludge composting process. Bioresour Technol 2009; 100(23): 5827-33. doi: 10.1016/j.biortech.2009.05.073.

33. Roca-Perez L, Martinez C, Marcilla P, Boluda R. Composting rice straw with sewage sludge and compost effects on the soil-plant system. Chemosphere 2009; 75(6): 781-7. doi: 10.1016/j.chemosphere.2008.12.058.

34. Rahmani HR, Moayeri M, Mazaheri Kouhanestani Z, Khodabakhsh N, Sharifi H. Studying some of the qualitative properties and concentration of heavy metals in dried sewage sludge from Shahin-Shahr WWTP in Isfahan. J Environ Sci Technol 2014; 16(2): 55-66.

35. Ponsá S, Pagans E, Sanchez A. Composting of dewatered wastewater sludge with various ratios of pruning waste used as a bulking agent and monitored by respirometer. Biosyst Eng 2009; 102(4): 433-43. doi: 10.1016/j. biosystemseng.2009.01.002.

36. Zhang S, Chen Z, Wen Q, Yang L, Wang W, Zheng J. Effectiveness of bulking agents for co-composting penicillin mycelial dreg (PMD) and sewage sludge in pilot-scale system. Environ Sci Pollut Res Int 2016; 23(2): 1362-70. doi: 10.1007/s11356-015-5357-y.

37. Zhang D, Luo W, Li Y, Wang G, Li G. Performance of cocomposting sewage sludge and organic fraction of municipal solid waste at different proportions. Bioresour Technol 2018; 250: 853-9. doi: 10.1016/j.biortech.2017.08.136.

38. Ghahramani E, Bagheri Ardabilian M, Zazouli MA, Ghorbanian Allahabad M. Principles of Compost Production Technology. 2nd ed. Tehran: Khaniran; 2012. [In Persian].

39. Kulikowska D, Sindrewicz S. Effect of barley straw and coniferous bark on humification process during sewage sludge composting. Waste Manag 2018; 79: 207-13. doi: 10.1016/j.wasman.2018.07.042. 